\title{
Menemukan Tujuan \\ Penggembalaan Kaum Muda Melalui Teknologi Media Sosial
}

\section{Yogas Lili Wiguna ${ }^{1}$}

\section{Latar Belakang Masalah}

D alam menghadapi daya persaingan ekonomi global pada tahun 2030 mendatang, survey PwC mengungkapkan posisi Indonesia sudah menempati posisi ke-9 sebagai negara ekonomi terbesar di bawah Tiongkok, AS, India, Jepang, Jerman, Rusia, Brasil, dan Perancis, serta masih mungkin naik ke posisi ke-4 dunia jika kondisi ekonomi politik Indonesia tetap stabil.2 Masa depan Indonesia semakin terlihat cerah dengan dukungan bonus demografi yang akan terjadi akan terjadi antara tahun 2020 hingga 2030, yang puncaknya akan terjadi pada tahun 2028-2030. Kondisi ini menjelaskan di mana 100 orang produktif menanggung 44 orang nonproduktif. Bonus demografi adalah sebuah formasi demografi penduduk antara jumlah penduduk berusia produktif yang diperkirakan mencapai 70 persen dan yang tidak produktif hanya 30 persen. ${ }^{3}$ Tentunya kondisi ini bisa berdampak positif terhadap pembangunan dan ekonomi negara yang sangat ditopang oleh generasi muda yang produktif sebagai generasi penerus bangsa di era digital dan globalisasi.

Merujuk juga kepada hasil survei Deloitte kepada generasi millenial pada tahun 2017, didapati bahwa 73 persen responden millenial memiliki opini yang positif dan siap berdampingan dengan generasi $\mathrm{Z}$ alias mereka yang kini berusia 18 tahun ke bawah. ${ }^{4}$ Generasi Z dianggap "melek" teknologi dan memiliki kemampuan kreativitas yang baik. Generasi yang merupakan digital natives ini telah mencapai mencapai 83,7 juta orang pada 2014 dan menempati peringkat ke- 6 di dunia. ${ }^{5}$ Bahkan diperkirakan netter Indonesia bakal mencapai 112 juta orang, mengalah-

1. Alumnus STT SAAT Malang (2008) dan sekarang melayani sebagai youth pastor di GKI Anugerah Bandung.

2. Szu Ping Can, "How the World will Look in 2050," http://www.telegraph.co.uk/finance/economics/11401466/How-theworld-will-look-in-2050.html (diakses 2 Oktober 2017).

3. Reja Hidayat, "Bonus Demografi dan 100 Tahun Sumpah Pemuda," https://tirto.id/bonus-demografi-dan-100-mhun-sumpahpemuda-bYwY (diakses 2 Oktober 2017).

4. The Dolitte Milenial Survey 2017, https://www2.deloitte.com/global/en/pages/aboutdeloitte/articles/millennialsurvey.html (diakses 2 Oktober 2017).

5. Istilah "digital natives" mengacu kepada suatu generasi yang tinggal sebagai penduduk te dan lahir dalam suatu sistem budaya yang sangat akrab dengan keterampilan dan gaya hidup terhadap teknologi digital. Dean Borgman, Foundations for Youth Ministry, edisi kedua (Grand Rapids: Baker, 2013), Edition Kindle, Location 212-214. 


\section{Kaum muda bukan menginginkan teknologi ataupun koneksi internet yang lebih baik, melainkan mereka membutuhkan suatu kedalaman hubungan dengan sesamanya, di mana kita menyebutnya sebagai aspek koinonia [persekutuan].}

kan Jepang di peringkat ke-5 yang pertumbuhan jumlah pengguna internetnya lebih lambat. ${ }^{6}$ Jejaring dunia sosial terus bertumbuh semakin kuat menjadi sebuah sistem yang mengatur hampir seluruh kehidupan sosial masyarakat hari ini.

Apa yang sebenarnya dapat kita lihat dari data-data statistik di atas dalam kaitannya dengan pelayanan terhadap kaum muda masa kini? Tidak bisa dipungkiri bahwa kita sedang berhadapan langsung (face to face) dengan generasi digital ini di tempat mereka berkumpul, yaitu di dunia digital (warganet) dan media-media sosial. ${ }^{7}$ Bagaimana kita menyikapi kondisi ini dan melayani mereka dengan efektif sementara hati dan pikiran mereka begitu terfokus pada jejaring dunia maya? Craig
Groeschel dalam bukunya yang berjudul Struggles memaparkan bagaimana pengaruh teknologi dan media sosial telah mengubah kehidupan kaum muda dari cara mereka menerima informasi, cara mereka berhubungan dengan sesama, cara mereka memandang diri sendiri dan mungkin apa yang mereka hargai dan percayai tentang Allah. ${ }^{8}$ Penulis percaya bahwa tugas pastoral terhadap kaum muda bukan berbicara tentang membentengi dengan aturan penggunaan, ataupun mencoba tetap relevan dengan menggunakan strategi melalui media-media sosial-digital, melainkan mengajak kita berpikir secara teologis tentang apa yang sebenarnya kaum muda alami dan rasakan dalam relasi komunitasnya.

Andrew Zirschky berpendapat fokus pastoral kita bukan terletak pada natur dari teknologi digital tersebut, melainkan pada natur dari gereja sebagai technological society. ${ }^{9}$ Kaum muda bukan menginginkan teknologi ataupun koneksi internet yang lebih baik, melainkan mereka membutuhkan suatu kedalaman hubungan dengan sesamanya, di mana kita menyebutnya sebagai aspek koinonia (persekutuan). Lebih lanjut Zirschky menempatkan fungsi pemuridan terhadap kaum muda perlu menyentuh aspek kebutuhan

6. Wicak Hidayat, “Pengguna Internet Indonesia Nomor Enam Dunia," http://tekno.kompas.com/read/2014/11/24/07430087/ Pengguna.Internet.Indonesia.Nomor.Enam.Dunia (diakses 2 Oktober 2017).

7. Beberapa dampak yang timbul dari digitalisasi informasi, yaitu informasi mudah ditemukan secara global, terjadinya revolusi komunikasi kepada dunia online, kebenaran menjadi sesuatu yang semu bahkan hoax, fokus kepada penggunaan gadgets, ser kehidupan berubah cepat dan instan. Ang Wie Hay, "Gaya Hidup Kristiani Era Globalisasi," Jurnal Youth Ministry 3 (Mei 2015): $52-$ 54 .

8. Craig Groeschel, \#Struggles (Pergumulan-Pergumulan): Mengikut Yesus di Dunia yang Terpusat pada Selfie, terj. Arvin Saputra, (Surabaya: Literatur Perkan Jawa Timur, 2016).

9. Andrew Zirschky, Beyond the Screen: Youth Ministry for the Connected but Alone Generation (Nashville: Abingdon Press, 2015), Kindle Edition, Location 139.

\section{Youllh}


intimasi dengan mengatakan, "discipleship must extend to forming youth into members of the body of Christ and inviting them to experience communion beyond connection -fellowship beyond the screen."

\section{Kebutuhan Berelasi bagi Generasi Digital}

Suatu data statistik penggunaan media sosial oleh kaum muda di Amerika Serikat, mencatat bahwa rata-rata kaum muda memiliki 3,5 gadget pribadi dan menggunakan 10,5 jam per hari di depan layar (screen time). Secara presentase kaum muda masa kini dapat dikatakan "almost constantly online" setiap harinya. ${ }^{10}$ Bagaimana dengan kaum muda di Indonesia? Dari 88,1 juta pengguna internet di Indonesia, 79 juta di antaranya merupakan pengguna media sosial aktif yang mayoritasnya adalah kaum muda. Angka yang tidak mengherankan, mengingat Indonesia merupakan salah satu negara teraktif di media sosial ${ }^{11}$ Di tengah gagasan pemerintah yang hendak menerapkan jam sekolah selama 40 jam (5 hari) dalam seminggu untuk semua sekolah nasional, berapa lama waktu yang dimiliki seorang remaja pada hari ini untuk berkomunikasi dengan komunitas dekatnya? Ketika gereja di kota-kota besar mulai kesulitan mencari waktu yang tepat untuk membuat suatu persekutuan kaum muda ataupun acara lain, sebenarnya mereka sudah mengisi waktunya dalam komunitas yang mereka inginkan, yaitu melalui media sosial seperti Facebook, Instagram, Line, Snapchat, Telegram, dan sebagainya.

Kebutuhan dan ekspresi relasi ini disebut Zirschky sebagai "presence in $a b$ sence" dibandingkan kondisi "absence in presence" yang sering dialami kaum muda yang kesepian ketika berada di tengahtengah kerumunan orang, seperti di sekolah, gereja, bahkan keluarga. ${ }^{12}$ Kita cenderung berpikir bahwa ada lebih banyak dampak negatif ketika memberi ruang lebih banyak bagi mereka untuk berinteraksi secara online dibanding pertemuan tatap muka (face to face). Namun sebenarnya ketika mereka mulai merasa bosan dan tidak dapat bagian dalam suatu pertemuan sehingga mereka akan mencari teman untuk berinteraksi.

Pada umumnya ada dua mitos dalam menyikapi penggunaan teknologi media sosial ini, yaitu pertama, dengan cara menggunakannya (employ) seluas-luasnya dengan tujuan menarik minat dan perhatian kaum muda. Kedua, dengan cara menarik diri (withdrawal) yaitu memutuskan koneksi guna mendapatkan kualitas hubungan yang lebih baik. Kita cenderung berpikir bahwa dengan menggunakan bantuan teknologi seperti undangan digital via Instagram, Line Group, Live Facebook, dan sebaga inya, maka mereka dapat merasakan kedekatan satu sama lain. Maka kemudian penggunaan

\footnotetext{
10. Amanda Lenhart, "Teens, Social Media and Technology Overview 2015," http://www.pewinternet.org/2015/04/09/teenssocial-media-technology-2015/ (diakses 2 Oktober 2017).

11. Lina Noviandari, "Statistik Pengguna Internet dan Media Sosial Terbaru di Indonesia," http://id.techinasia.com/talk/statistikpengguna-internet-dan-media-sosial-terbaru-di-indonesia (diakses 2 Oktober 2017).

12. Zirschky, Beyond the Screen, 199.
} 
teknologi ini hanya sebatas sarana untuk membuat kegiatan-kegiatan serta interaksi pelayanan kaum muda yang lebih relevan dan menarik. Namun, hal itu tidak akan terjadi jika interaksi tatap muka (face to face) tersebut gagal untuk memenuhi aspek kehadiran dalam hubungan yang dibangun. Contohnya dalam kelompok kecil, jika interaksi tetap terjadi dalam satu arah, dari pemimpin kepada anggota, maka akan cenderung kembali kepada pembahasan materi dan target-target disiplin rohani yang perlu dibangun, namun tidak pernah menyentuh pengalaman hidup setiap anggotanya. Sehingga, ketika semua media dan teknologi itu kita buang, maka sebenarnya hubungan relasi antar personal tetap tidak pernah terjadi dan yang ada hanya sebatas ungkapan "see you next Sunday community."13

Jika mitos yang pertama adalah dengan menggunakan teknologi media sosial agar pelayanan terhadap kaum muda lebih relevan, maka yang kedua adalah kebalikannya, yaitu dengan cara memisahkan kaum muda dari semua bentuk teknologi tersebut. Kita akan meminta mereka meletakkan semua gadgets mereka ketika hadir dalam pertemuan-pertemuan kaum muda. Jika kita berpikir bahwa perubahan budaya yang terjadi semata-mata karena semakin banyaknya alat-alat teknologi tersebut, maka ketika kita dapat melawan semua kehadiran teknologi tersebut, maka semuanya akan kembali normal. Bagaimana jika masalahnya bukan pada alat (devices)? Ketika semua baterai smartphone itu habis dan tidak lagi bisa digunakan, kenyataannya interaksi tatap muka tetap tidak bisa membangun suatu kedalaman hubungan. Memang bentuk detoks perlu dilakukan untuk menolong kaum muda memiliki waktu dalam merefleksikan hubungan dengan sesamanya tanpa alat-alat tersebut. ${ }^{14}$ Namun cara ini sebenarnya tidak berhubungan langsung dengan bagaimana mereka berelasi dengan sesamanya dalam sistem budaya yang individualismenya tinggi.

Kita perlu menyadari adanya suatu sistem yang beroperasi dalam suatu budaya sosial yang terbentuk dengan seiring perkembangan teknologi tersebut. Sosiolog Manuel Castells menyebutnya sebagai networked individualism, suatu sistem yang dominan dari budaya sosial di mana relasi dibentuk oleh teknologi sosial dan di saat yang sama juga mendorong keinginan untuk terus menerus menggunakan teknologi sosial. ${ }^{15}$ Di masa yang lalu komunitas itu dibentuk oleh ruang fisik di mana relasi itu terjadi di lingkungan rumah, sekolah, gereja dan sebagainya. Namun, masakini komunitas

13. Zirschky, Beyond the Screen, 1588. la menyebutnya sebagai "thirty seconds of friendliness" di mana kit hanya menggunakan sedikit waktu dalam pertemuan ibadah minggu untuk saling mengucapkan sapaan dan salam damai kepada orang lain di sekeliling ki sebagai gambaran persekutuan yang ada.

14. Groeschel mengusulkan adanya refleksi terhadap delapan nilai hidup untuk memulihkan keseimbangan terhadap kecanduan teknologi medisa sosial, yaitu kecukupan diri, keintiman, keotentikan, belas kasih, integritas, ka-ka penyemangat, ibadah, dan istirahat. Groeschel, \#Struggles, 16.

15. Manuel Castells, The Internet Galaxy: Reflection on the Internet, Business, and Society (London: Oxford University, 2003), 130-131.

\section{$76 \operatorname{moulf}_{\text {ministry }}$ | Mei 2016}


itu didefinisikan sebagai "networks of interpersonal ties that provide sociability, support, information, a sense of belonging, and social identity." ${ }^{16}$ Kita melihat adanya pergeseran definisi komunitas dari suatu lingkungan di mana saling memiliki (space) kepada dukungan sosial (feeling). Tempat dan ruang fisik secara geografis tidak lagi mengikat suatu hubungan, namun ditentukan oleh orang-orang yang bersosialisasi di dalamnya dan saling berinteraksi (person to person). Identitas kaum muda tidak hai dibentuk pada suatu lingkungan saja, tetapi dari banyak lingkungan (social media group) di mana mereka berinteraksi di dalamnya. Mereka dengan sangat mudah akan membuat lingkaran grup komunitasnya, katakanlah di Instagram, dengan cara terus menjaga agar grup itu tetap hidup dengan membuat konten dan update status yang menarik untuk mendapatkan banyak likes dan followers, namun mereka juga selektif dalam memilih teman. Oleh karena itu, tantangan bagi pelayanan kaum muda adalah tidak bisa berpuas diri hanya pada tawaran penggunaan teknologi sosial yang lebih menarik, tetapi kitaperlu memberikan mereka suatu pintu masuk kepada komunitas yang memiliki sistem dan proses yang lebih baik, di mana aspek kehadiran dan intimasi dirasakan.

Kaum muda mencari kehadiran dan bukan hanya koneksi relasi (communion beyond connection), di mana mereka dapat mengalami pengalaman berjalan ber- sama, dikenal dan mengenal satu dengan yang lainnya merupakan konsep yang seutuhnya dari fungsi koinonia gereja. Sejak peristiwa Pentakosta, gereja mulamula dikatakan, "mereka bertekun dalam pengajaran rasul-rasul dan dalam persekutuan. Dan mereka selalu berkumpul untuk memecahkan roti dan berdoa" (Kis. 2:42). Kata koinonia dalam bahasa Yunani sering diterjemahkan menjadi persekutuan ( $\mathrm{fel}$ lowship). Namun, betapa seringnya kita mengidentikkan persekutuan itu dengan kegiatan bersama kaum muda (youth meetings) dan kehidupan saling berbagi (sharing) digantikan sebatas berbagi foto bersama dan lain sebagainya.

Gereja perlu menyediakan suatu alternatif dari budaya jejaring sosial (networked culture) sebagai sarana mengalami Kristus yang hadir di tengah-tengah mereka, di mana gereja dapat dilihat sebagai gambaran tubuh Kristus yang saling menyatu dan memperhatikan (1Kor. 12: 25-26). Mengalami pembentukan dan pertumbuhan serupa Kristus artinya dibentuk di dalam komunitas tubuh Kristus itu sendiri. Komunitas Kristen bukan hanya bicara tentang berbagi pengalaman, namun juga tempat berbagi nilai dasar kehidupan dan visi dari kehidupan itu sendiri. ${ }^{17}$ Tugas pelayanan terhadap kaum muda masa kini bukan berarti menggantikan bentuk pertemuan rutin kaum muda kepadabentuk interaksi online, melainkan menjadi tantangan bagi gereja dan pembina kaum muda untuk memberi makna

16. Zirschky, Beyond the Screen, 921.

17. Tod E. Bolsinger, It Takes a Church to Raise a Christian: How Community of God Transform Lives (Grand Rapids: Brazos, 2004), 24-25. 
dan kedalaman hubungan dari suatu pertemuan bersama sebagai gambaran tubuh Kristus yang sebenarnya. Mungkin sebagian kita berpendapat bahwa selama ini bentuk-bentuk pertemuan rutin kaum muda seperti ibadah dan kelompok kecil sudah mengakomodasi dengan banyak ide-ide (roleplay) yang kreatif dan menarik sehingga mereka nyaman berada di dalamnya. Namun, kita perlu melihat apakah setiap interaksi sudah menjadi bentuk aktif secara relasional dan bukan informasional belaka. Oleh sebab itu, pengajaran yang diberitakan Paulus kepada jemaat di Korintus lebih berbicara tentang ide koinonia (doing life together) yang melawan sistem budaya sosial pada zaman tersebut.

\section{Tantangan terhadap Komunitas dalam Jemaat di Korintus}

Pada Surat 1 Korintus pasal 10-12, Paulus menasihatkan jemaat di Korintus tentang perjamuan malam yang mereka lakukan bukan sebagai makanan yang mereka makan, tetapi sebagai cara untuk menantang budaya sosial dari kerajaan Romawi saat itu dengan memberikan pemahaman akan konsep koinonia yang benar. Adanya permasalahan di dalam jemaat tentang perpecahan yang terjadi disebabkan karena mereka lebih sibuk memakan makanan mereka sendiri dan tidak menghargai perjamuan malam (communion) sebagaimana yang Tuhan
Yesus teladankan sebagai The Lord's Supper. Paulus mengatakan, "apabila kamu berkumpul, kamu bukanlah berkumpul untuk makan perjamuan Tuhan. Sebab pada perjamuan itu tiap-tiap orang memakan dahulu makanannya sendiri, sehingga seorang lapar dan yang lain mabuk" (1Kor. 11:20-21).

Hadir dalam perjamuan malam dalam konteks budaya Romawi adalah ibarat kita ingin melihat atau mempertunjukkan status sosial dan prestasi seseorang. ${ }^{18}$ Pada suatu perjamuan malam, tuan rumah akan mengundang tamu-tamunya dan mulai menempatkan posisi duduk mereka secara status sosial. Semakin jauh posisi duduknya dari tuan rumah, maka mereka akan mendapatkan urutan dan bentuk makanan yang berbeda atau bahkan yang tersisa. Sering kali makanan tersebut termasuk makanan yang sudah dipersembahkan kepada dewa atau ilah lain. ${ }^{19}$ Sistem kompetisi sosial yang dipertontonkan inilah yang ditentang Paulus dengan menjelaskan pemahaman bentuk partisipasi (koinonia) di dalam Kristus. Paulus mengatakan, "bukankah cawan pengucapan syukur, yang atasnya kita ucapkan syukur, adalah persekutuan darah Kristus? Karena roti adalah satu, maka kita, sekalipun banyak, adalah satu tubuh, karena kita semua mendapat bagian dalam roti yang satu itu" (1Kor. 10:1617). Artinya setiap cawan anggur yang diminum dan roti yang dimakan melam-

18. Craig S. Kenner, 1-2 Corinthians, New Cambridge Bible Commentary (New York: Cambridge University Press, 2005), 96-97 19. Ben Witherington, Conflict and Community in Corinth: A Socio-Rhetrorical Commentary on 1 and 2 Corinthians (Downers Grove: Eerdmans, 1995), 241.

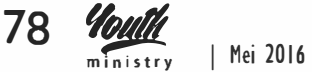




\section{Gereja bukan hanya menjadi tempat ekplorasi talenta dan aktualisasi bagi kaum muda, tetapi harus kembali kepada panggilannya sebagai komunitas tubuh Kristus yang memfasilitasi terjadinya pengalaman untuk bergantung kepada Tuhan dan hadir bagi sesama.}

bangkan darah dan tubuh Kristus sebagai satu kesatuan di dalam dan bersama dengan Kristus sendiri. ${ }^{20}$

Pemahaman yang benar akan konsep kesatuan dalam tubuh Kristus dibuktikan dengan cara hidup bersama dalam komunitas Kristen dan diekspresikan dalam kesetaraan status sosial yaitu saling menerima, saling melayani, dan saling mengasihi sebagaimana teladan Kristus. Ketika gereja hanya menjadi tempat perkumpulan sosial, makayang terjadi adalah sebuah sistem hirarki yang membedabedakan jemaat di mana setiap pertemuan seperti perjamuan malam menjadi "social operating system" untuk mengejar nilai, status, dan pengakuan yang tiada akhirnya. ${ }^{21}$ Bukankah itu yang kita temui dalam citra diri yang dibentuk kaum muda dalam media-media sosialnya. Konsep relasi dalam media sosial digital dicirikan dengan memiliki kontak relasi yang lebih luas dan cara yang lebih kreatif untuk berinteraksi. Di saat yang sama, kaum muda haus mencari seseorang (someone) melalui jejaring sosial untuk bisa diajak berbicara, namun sedikit mendapatkan mereka yang mau berdiri di samping mereka. Tidak heran mereka lebih mudah merasa sendiri di tengah-tengah kerumunan orang.

Konsep koinonia yang benar tentunya tidak bisa dipisahkan dari pemahaman akan Allah Trinitas. Relasi di antara pribadi-pribadi Allah dalam Trinitas digambarkan sebagai perichoresis (dancing around) antara Bapa, Putra, dan Roh Kudus. Ketiganya membentuk kekekalan yang di dalamnya merupakan keberadaan dan esensi Ilahi. ${ }^{22}$ Istilah ini diperkenalkan oleh John Damascus, seorang teolog Yunani, untuk menjelaskan kesatuan natur dan adanya relasi yang saling bergantung. Sedangkan Jurgen Moltmann lebih menekankan pada individu-individu Ilahi yang saling berelasi, tinggal, dan hadir untuk satu sama lainnya. ${ }^{23}$ Setiap individu (kaum muda) yang diciptakan dalam gambar dan rupa Allah perlu aktif dalam menyatakan kehadirannya kepada sesamanya, melalui atribut Trinitas, yaitu kasih yang melampaui kebutuhan dan keinginan diri, kasih yang hadir (presence) dan memberi diri

20. Boenhoffer mengatakan makna komunitas Kristen dengan sangat tepat yaitu, "Christianity means community through Jesus Christ and in Jesus Christ. No Christian community is more or less than this." Dietrich Bonhoeffer, Life Together (New York: HarperSanFransisco, 1954), 21.

21. Zirschky, Beyond the Screen, 1432.

22. Rosyeline Tinggi, "Peranan Komunitas dalam Proses Individuasi Remaja," Jurnal Youth Ministry 2 (Mei 2014 ): 41.

23. Jurgen Moltmann, The Trinity and the Kingdom (Minneapolis: Fortress Press, 1993), 8. 
(selfless). ${ }^{24}$ Paulus menjelaskan fungsi setiap anggota tubuh Kristus yang saling merasakan ketika ada satu anggota yang menderita, maka semua anggota turut menderita, serta jika ada satu anggota dihormati, semua anggota turut bersukacita (1Kor. 12:26).

Bagaimana konsep koinonia ini terimplementasi dalam relasi kaum muda? Aspek kehadiran bagi kaum muda di era media sosial digital ini tidak selalu berarti hadir secara fisik ataupun duduk bersama di suatu tempat, namun dengan hadir untuk seseorang dengan cara yang aktif untuk memberi diri, perhatian, dan pikiran bersama (Rom. 12:15). ${ }^{25}$ Kita bukan semata-mata seperti merasa hadir untuk saudara kita yang sedang bergumul atau mengalami kesulitan (feeling of being there), namun lebih dari itu dengan mencurahkan semua energi kita untuk menolongnya (the feeling being with) baik itu perhatian, waktu, materi, dan sebagainya. Praktik kehadiran dan keterlibatan yang bersifat personal bagi kaum muda akan menjadi suatu pengalaman untuk melihat kehadiran dan pekerjaan Allah di dalam hidup mereka. Dengan cara demikianlah kita membebaskan kaum muda dari perasaan cemas dan pengejaran atas pengakuan identitas mereka kepada kebebasan untuk hadir bagi sesamanya." 26

\section{Penutup}

Sebagai pembina kaum muda, kita perlu mengingat bahwa tidak ada seorang pun yang dapat melakukan penggembalaan dan pelayanan terhadap kaum muda seorang diri. Sebagaimana halnya Tuhan menempatkan kita dalam suatu komunitas maka tugas pastoral ini perlu dikerjakan bersama-sama sebagai satu tubuh Kristus. Amy Jacober menyebut tugas pastoral ini sebagai "an affirmation, philosophical, and scripturally, that we are intended to serve as a team - that we may released form the tyranny of competition and proving our worth over and above others." 27 Kita diajak bukan hanya berkomunikasi melalui khotbah dan pengajaran terhadap kaum muda, namun di saat yang sama kita perlu lebih banyak mendengar tentang apa yang mereka alami dan rasakan. ${ }^{28}$ Gereja bukan hanya menjadi tempat eksplorasi talenta dan aktualisasi bagi kaum muda, tetapi harus kembali kepada panggilannya sebagai komunitas tubuh Kristus yang memfasilitasi terjadinya pengalaman untuk bergantung kepada Tuhan dan hadir bagi sesama. Bolsinger menjelaskan konsep eklesiologi ini sebagai "a spirituality of fellowship and following which oriented within the biblical vision of a people of God who are on journey with God, expressing the reign of God, following God in a trust and obedience and

24. Zirschky, Beyond the Screen, 1641

25. Bolsinger mengatakan, "therefore, Christian communities are formed intentionally through expressed Christian faith and commitment to the community." Bolsinger, It Takes a Church, to Raise a Christian, 75.

26. Zirschky mengatakan, "being released from the need to accomplish the self, to gain validity and status, youth are thus free to truly be present with others. They are set free for relationality and for presence with and within others. Zirschky, Beyond the Screen, 1952.

27. Houston Heflin, Youth Pastor: The Theology and Practice of Youth Ministry (Nashville: Abingdon Press, 2009$), 7$.

28. Tim Elmore, Generation iY: Secret Connecting with Today's Teen and Young Aduls in the Digital Age, edisi kedua (Atlanta: Poet Gardener, 2015), 237 
being tranformed into the likeness of the Triune God in process." 29

Panggilan hidup bersama dalam Kristus akan mendorong kita untuk tidak semata-mata memperhatikan kaum muda hanya sebatas kapabilitas, kreatifitas, ataupun kontribusi mereka yang terlihat menonjol bagi kepentingan pelayanan atau kegiatan kaum muda di gereja, melainkan kita perlu menjadi komunitas yang hadir bagi semua orang dan berpartisipasi di meja perjamuan Tuhan. Rasul Paulus tidak melihat apa yang berada di sekitar meja perjamuan makan seperti bantalan duduk, hiasan meja, bentuk cawan, dan piringan roti sebagai masalah ketika mereka berkumpul bersama. Maka seperti halnya media sosial yang kita gu- nakan sekarang baik itu Facebook, Instagram, dan lain sebagainya, bukan menjadi esensi masalah, melainkan karakter penggunanya yang membuat sistem budaya sosial yang terbentuk tidak lagi menggambarkan komunitas Kristen. Setiap pelayan kaum muda perlu memberikan dukungan kepada mereka untuk menggunakan media sosial dengan tujuan yang lebih dalam untuk mengalami komunitas Kristen yang penuh dengan kasih karunia. Di tengah gencarnya kasus bullying yang dilakukan kaum muda di media sosial, kita dipanggil untuk menghadirkan kasih Allah melalui hikmat dan kepekaan yang Roh Kudus berikan guna menumbuhkan suatu komunitas koinonia yang disertai bentuk tindakan nyata.

29. Bolsinger, It Takes a Church, to Raise a Christian, 169. 


\section{Daftar Pustaka}

\section{Buku}

Bolsinger, Tod E. It Takes a Church to Raise a Christian: How Community of God Transform Lives. Grand Rapids: Brazos, 2004.

Bonhoeffer, Dietrich. Life Together. New York: HarperSanFransisco, 1954.

Borgman, Dean. Foundations for Youth Ministry. Grand Rapids: Baker, 2013. Edisi Kindle.

Castells, Manuel. The Internet Galaxy: Reflection on the Internets, Business, and Society. London: Oxford University, 2003.

Elmore, Tim. Generation iY: Secret Connecting with Today's Teen and Young Adults in the Digital Age. Atlanta: Poet Gardener, 2015.

Groeschel, Craig. \#Struggles (\#Pergumulan-Pergumulan): Mengikut Yesus di Dunia yang Terpusat pada Selfie. Diterjemahkan oleh Arvin Saputra. Surabaya: Literatur Perkantas Jawa Timur, 2016.

Heflin, Houston. Youth Pastor: The Theology and Practice of Youth Ministry. Nashville: Abingdon Press, 2009.

Kenner, Craig. 1-2 Corinthians. New Cambridge Bible Commentary. New York: Cambridge University Press, 2005.

Moltmann, Jurgen. The Trinity and the Kingdom. Minneapolis: Fortress Press, 1993.

Tinggi, Rosyeline. "Peranan Komunitas dalam Proses Individuasi Remaja." Jurnal Youth Ministry 2 (Mei 2014): 39-45.

Wie Hay, Ang. "Gaya Hidup Kristiani Era Globalisasi." Jurnal Youth Ministry 3 (Mei 2015): 51-59.

Witherington, Ben. Conflict and Community in Corinth: A Socio-Rhetrorical Commentary on 1 and 2 Corinthians. Downers Grove: Eerdmans, 1995. 
Zirschky, Andrew. Beyond the Screen: Youth Ministry for the Connected but Alone Generation. Nashville: Abingdon Press, 2015. Edisi Kindle.

\section{Internet}

Hidayat, Reja. "Bonus Demografi dan 100 Tahun Sumpah Pemuda." http://tirto.id/ bonus-demografi-dan-100-tahun-sumpah-pemuda-bYwY (diakses 2 Oktober 2017).

Hidayat, Wicak. "Pengguna Internet Indonesia Nomor Enam Dunia." http://tekno. kompas.com/read/2014/11/24/07430087/Pengguna.Internet.Indonesia.No mor.Enam.Dunia (diakses 2 Oktober 2017).

Lenhart, Amanda. "Teens, Social Media, and Technology Overview 2015." http://www. pewinternet.org/2015/04/09/teens-social-media-technology-2015/ (diakses 2 Oktober 2017).

Noviandari, Lina. "Statistik Pengguna Internet dan Media Sosial Terbaru di Indonesia." http://id.techinasia.com/talk/statistik-pengguna-internet-dan-media-sosialterbaru-di-indonesia (diakses 2 Oktober 2017).

Ping Can, Szu. "How the World will Look in 2050." http://www.telegraph.co.uk/finance /economics/11401466/How-the-world-will-look-in-2050.html (diakses 2 Oktober 2017). 